\title{
CORRECTIONS
}

\section{Why we can't trust clinical guidelines}

Due to an editing error, the table in this Feature does not correctly display the competing interests for the author Jagoda (BMJ 2013;346:f3830, doi:10.1136/bmj.f3830). The published table incorrectly lists "FERNE only" as a competing interest for Jagoda and does not specify that this interest was disclosed. Furthermore, Genentech and AstraZeneca should have been listed as competing interests, which were both undisclosed. The corrected version of the table can be found here.

Cite this as: BMJ 2013;346:f3998

๑ BMJ Publishing Group Ltd 2013 


\section{Table}

Table 1 [ [CORRECTED VERSION] Competing interests of authors of American College of Emergency Physicians and the American Academy of Neurology guidelines on alteplase

\begin{tabular}{lcc}
$\begin{array}{l}\text { Author } \\
\text { Edlow }\end{array}$ & $\begin{array}{c}\text { Competing interest } \\
\text { Smith }\end{array}$ & $\begin{array}{c}\text { Disclosed } \\
\text { FERNE }\end{array}$ \\
\hline Stead & Genentech & Yes \\
\hline Gronseth & None & \\
\hline Messe & Boehringer Ingelheim & Yes \\
\hline Jagoda & Boehringer Ingelheim & Yes \\
\hline Wears & FERNE & Yes \\
\hline Decker & Genentech & No \\
\hline
\end{tabular}

${ }^{*}$ It is not clear if the author was aware of the source of FERNE funding. 